\title{
Seasonal Variations of Extractive Components in the Muscle of Disk Abalone ${ }^{* 1}$
}

\author{
Hiroko Watanabe, ${ }^{* 2}$ Hideaki Yamanaka, ${ }^{* 2}$ and Hiroshi Yamakawa*s \\ (Received December 10, 1991)
}

\begin{abstract}
Seasonal variations of extractive components were examined in the muscle of disk abalone Haliotis discus collected from the coast of Amatsukominato, Chiba Prefecture at intervals of two or three months from July 1990 to July 1991.

The moisture content was highest in December after spawning season, thereafter decreased and became lowest in May. The total amount of ATP and its related compounds was highest in September. AMP was detected in high amounts from July to September. The level of glycogen was high in summer (over $6 \%$ ), decreased remarkably in the spawning season and low in winter. Succinate was high in amounts from May to September. The total amount of free amino acids was highest in September and decreased to half in other months. The contents of glutamic acid, glycine, and AMP which are taste-active components were highest $(470 \mathrm{mg} / 100 \mathrm{~g})$ in September and lowest $(130 \mathrm{mg} / 100 \mathrm{~g})$ in February. Present study can demonstrate that disk abalones are palatable in summer, and watery and unpalatable in winter, which is generally told in Amatsukominato district.
\end{abstract}

In fishes and shellfishes there exists the most tasteful season when large amounts of catch is observed. However, little information is available for seasonal variations in the levels of extractive components except for some bivalves such as short-neck clam, ${ }^{1)}$ freshwater clam, ${ }^{1)}$ oyster, ${ }^{1,2)}$ and so forth.

In this paper were examined the seasonal variations of extractive components in the muscle of disk abalone in relation to the umami taste.

\section{Materials and Methods}

\section{Samples}

From July 1990 to July 1991, three natural live disk abalones Haliotis discus were collected six times on the coast of Amatsukominato, Chiba Prefecture at intervals of two or three months. The averages of shell length and body weight were $123 \mathrm{~mm}$ and $247 \mathrm{~g}$, respectively. Five grams of muscle was homogenized with $20 \mathrm{ml}$ of $6 \%$ perchloric acid in an ice-cooled homogenizer. The suspension was centrifuged at $3,000 \times \mathrm{g}$ for $15 \mathrm{~min}$ and the procedure was repeated. The combined supernatants were made up to $50 \mathrm{ml}$ and neutralized with potassium hydroxide. The extract was used in the following analyses.

Determination of ATP and Its Related Compounds ATP and its related compounds were determined by high performance liquid chromatography (HPLC) according to the method of Matsumoto and Yamanaka. ${ }^{3)}$ HPLC was performed on an Asahipak GS-320 (Asahi Chemical Industry Co.) column $(7.6 \times 500 \mathrm{~mm})$ with $200 \mathrm{mM} \mathrm{NaH}_{2}-$ $\mathrm{PO}_{4}(\mathrm{pH} 2.9$ ) and the absorbance at $260 \mathrm{~nm}$ was measured.

\section{Determination of Glycogen}

After 0.1 to $0.2 \mathrm{~g}$ of muscle was extrated in $2 \mathrm{ml}$ of heated $30 \%$ potassium hydroxide, absolute ethanol was added to the solution and glycogen was precipitated. The obtained glycogen was hydrolyzed with $1 \mathrm{M}$ sulfuric acid and glucose formed was determined by the combination of mutarotase and glucose oxidase (Glucose CTest Wako).

*1 This study was presented at the annual meeting of the Japanese Society of Scientific Fisheries, Sanriku, Iwate, October, 1991.

*2 Department of Food Science and Technology, Tokyo University of Fisheries, Konan, Minato, Tokyo 108, Japan (洨辺裕子, 山中英明: 東京水産大学食品生産学科).

*3 Department of Aquatic Biosciences, Tokyo University of Fisheries, Konan, Minato, Tokyo 108, Japan (山川 紭: 東京水産大学資源育成学科). 
Determination of $\mathrm{D}$ - and $\mathrm{L}-$ Lactate

D- and L-lactate were determined by the use of F-kit (Boehringer Mannheim Co.) based on enzymatic analysis.

Determination of Succinate, Malate, and Acetate

The organic acids were determined by HPLC on a Shim-pack SCR-102H column $(8.0 \times 150$ $\mathrm{mm}$ ). The elution was performed with $5 \mathrm{~mm}$ p-toluenesulfonic acid containing $20 \mathrm{~mm}$ BisTris and $100 \mu_{\mathrm{M}}$ EDTA. The eluate was monitored by a conductivity detector (Shimadzu CDD-6A).

\section{Determination of Free Amino Acids}

Free 2 mino acids were determined by an amino acids analyzer (Hitachi 835-50 Type).

\section{Determination of Homarine}

Homarine was determined by the same HPLC method and conditions employed in the determination of ATP and its related compounds.

\section{Results and Discussion}

The seasonal changes in degree of stoutness of disk abalone obtained by the average of three samples are shown in Table 1 . The other results shown below are also the averages of three samples. The degree of stoutness was high in September 1990, February and May 1991. Since sea trumpet, kajime, and wakame on which disk abalone feed, proliferate from February to May, disk abalones are considered to become stout in this season. The growth of gonad was also observed in disk abalone collected in September and December. It should be noted that the low value of stoutness was observed in December. This is due to the spawning season of disk abalones extending from the middle of October to the end

Table 1. Seasonal changes in degree of stoutness and moisture content in the muscle of disk abalone

\begin{tabular}{lcc}
\hline $\begin{array}{c}\text { Period of } \\
\text { sampling }\end{array}$ & $\begin{array}{c}\text { Degree of } \\
\text { stoutness }\end{array}$ & $\begin{array}{c}\text { Moisture } \\
\text { content }(\%)\end{array}$ \\
\hline July, 1990 & 0.115 & - \\
September, 1990 & 0.130 & 71.0 \\
December, 1990 & 0.123 & 76.5 \\
February, 1991 & 0.133 & 75.2 \\
May, 1991 & 0.136 & 59.8 \\
July, 1991 & 0.129 & 61.5 \\
\hline Body weight &
\end{tabular}

\footnotetext{
* Body weight $(\mathrm{g}) / 10^{3} /$ (shell length $\left.(\mathrm{mm})\right)^{3}$
}

of December. According to the report by Sakai, ${ }^{42}$ the period of stoutness in Yezo abalone Haliotis discus hannai was observed from February to July and little growth in winter. The growth of Yezo abalones was also low from August to September when the gonad was matured and the spawning was done. The results of disk abalone (Table 1) were almost the same as those of Yezo abalones.

The results of moisture contents are also shown in Table 1. After spawning season (in December) the moisture content in disk abalones was highest $(76.5 \%)$ and thereafter decreased to the level of about $60 \%$ in May and July. These results substantiate the empirical knowledge that local people perceive disk abalones to be watery in winter, compared with those in summer.

In Fig. 1 are shown the seasonal changes in contents of ATP and its related compounds in the muscle of disk abalone. In September the total amount of ATP and related compounds was

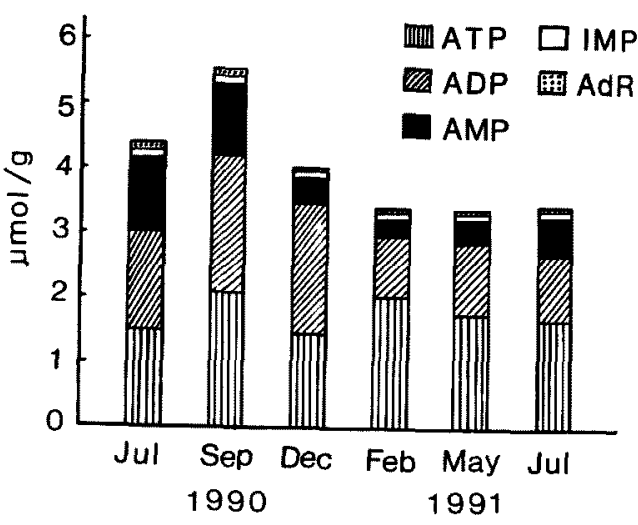

Fig. 1. Seasonal changes in contents of ATP and its related compounds in the muscle of disk abalone.

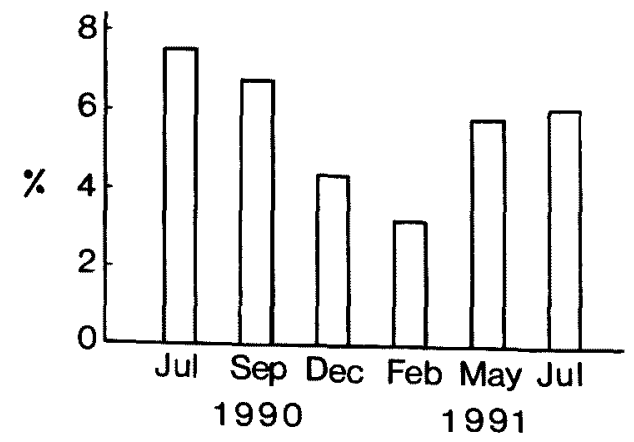

Fig. 2. Seasonal changes in content of glycogen in the muscle of disk abalone. 
highest $(5.5 \mu \mathrm{mol} / \mathrm{g})$. ATP and ADP were major components and a fairly large amount of AMP was detected in September and July. Small amounts of IMP and adenosine (AdR) were detected all the year round, indicating that AMP

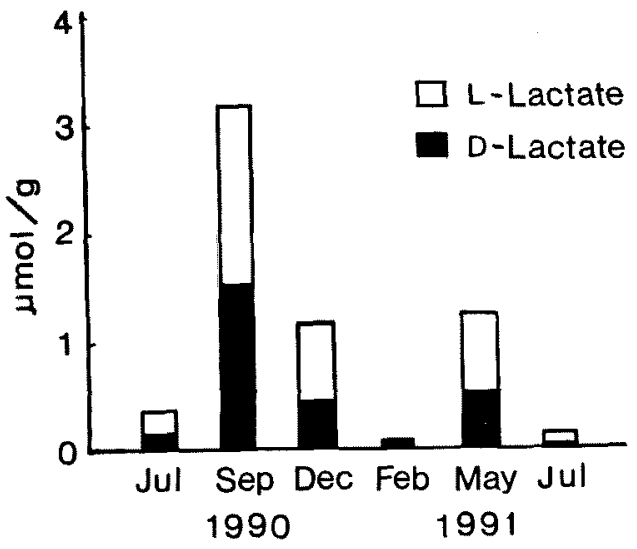

Fig. 3. Seasonal changes in contents of $D-$ and $L$ lactate in the muscle of disk abalone. was metabolized through two pathways. In the muscle of the cultured ascidian ${ }^{52}$ a marked seasonal change was observed in the sum of nucleotides and related compounds; the value found in September was nearly 4 times as high as that found in January. It has been also reported that smaller amounts of nucleotides

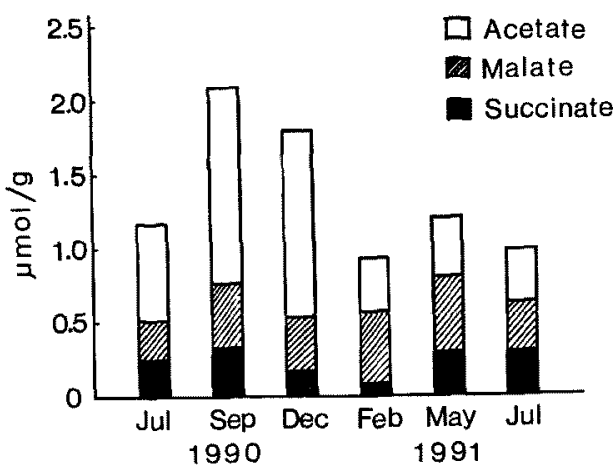

Fig. 4. Seasonal changes in contents of succinate, malate and acetate in the muscle of disk abalone.

Table 2. Seasonal changes in contents of free amino acids in the muscle of disk abalone

$(\mathrm{mg} / 100 \mathrm{~g})$

\begin{tabular}{|c|c|c|c|c|c|c|}
\hline \multirow{2}{*}{ Amino acids } & \multicolumn{3}{|c|}{1990} & \multicolumn{3}{|c|}{1991} \\
\hline & Jul. & Sep. & Dec. & Feb. & May & Jul. \\
\hline Taurine & 1138.6 & 1281.4 & 1031.0 & 1296.6 & 1173.1 & 1118.3 \\
\hline Aspartic acid & 9.2 & 53.9 & 42.1 & 69.6 & 15.5 & 5.5 \\
\hline Hydroxyproline & 1.2 & 3.7 & 23.9 & 2.7 & 5.7 & 5.7 \\
\hline Threonine & 32.7 & 63.3 & 20.2 & 29.0 & 34.0 & 34.3 \\
\hline Serine & 20.9 & 138.9 & 20.6 & 20.6 & 23.1 & 19.4 \\
\hline Glutamic acid & 37.6 & 163.2 & 77.6 & 38.2 & 36.6 & 32.1 \\
\hline Glutamine & 191.1 & 799.2 & 214.2 & 118.9 & 158.6 & 107.6 \\
\hline Sarcosine & 11.7 & 3.1 & 6.2 & 3.7 & 1.7 & 7.4 \\
\hline Proline & 32.3 & 50.4 & 18.1 & 20.0 & 34.4 & 30.0 \\
\hline Glycine & 136.8 & 278.2 & 94.5 & 80.2 & 82.3 & 109.1 \\
\hline Alanine & 30.5 & 152.7 & 57.1 & 25.6 & 28.1 & 27.2 \\
\hline Citrulline & 0.2 & 5.4 & 1.5 & 0 & 0.7 & 0.3 \\
\hline Valine & 12.2 & 47.2 & 11.9 & 9.3 & 14.0 & 10.6 \\
\hline Cystine & 0.4 & 2.8 & 2.2 & 4.8 & 0.1 & 0 \\
\hline Methionine & 4.1 & 6.6 & 3.7 & 2.1 & 4.5 & 2.7 \\
\hline Isoleucine & 6.8 & 20.7 & 6.7 & 4.2 & 6.0 & 4.7 \\
\hline Leucine & 10.2 & 235.4 & 247.4 & 59.7 & 8.9 & 6.6 \\
\hline Tyrosine & 18.2 & 3.6 & 12.3 & 4.6 & 20.1 & 15.6 \\
\hline Phenylalanine & 10.6 & 16.4 & 7.7 & 5.8 & 12.2 & 8.3 \\
\hline Tryptophan & 9.9 & 59.3 & 8.3 & 7.2 & 11.1 & 7.4 \\
\hline Histidine & 17.8 & 10.9 & 5.8 & 9.6 & 11.3 & 8.9 \\
\hline Ornithine & 4.3 & 8.0 & 5.9 & 2.9 & 4.2 & 5.0 \\
\hline Ammonia & 0.9 & 8.5 & 6.9 & 10.7 & 3.6 & 1.4 \\
\hline Lysine & 24.2 & 37.1 & 8.4 & 17.6 & 20.3 & 29.8 \\
\hline Arginine & 198.0 & 369.7 & 197.6 & 126.4 & 195.0 & 268.4 \\
\hline Total amounts & 1960.4 & 3819.6 & 2132.4 & 1970.0 & 1905.1 & 1866.3 \\
\hline
\end{tabular}


were detected in the muscle of mackerel ${ }^{8)}$ and ascidian $^{\text {7) }}$ which were caught in the spawning season.

Seasonal changes in content of glycogen are shown in Fig. 2. Glycogen varied obviously with the seasons. Its level was high in summer (over $6 \%$ ), decreased remarkably in the spawning season and was lowest $(3.2 \%)$ in February. These results are similar to those of ascidian muscle ${ }^{8)}$ glycogen contents are high from May to September (ca. $8 \%$ ) and low from December to March (2-4\%), and a high content of glycogen in summer is consistent with the palatable season of ascidian. In the muscle of disk abalone there existed a reverse correlation between moisture content and glycogen level. It is reported that in the spawning season glycogen content decreased markedly and moisture content increased in the muscle of oyster. ${ }^{1)}$ Glycogen itself is found to be tasteless, but reported to elevate continuity, fullness, complexity, and overall preference, when being added to a synthetic extract from scallop muscle. ${ }^{\text {? }}$

Figure 3 shows seasonal changes in contents of $\mathrm{D}$ - and L-lactate as the glycolytic end products. D- and L-lactate were detected in high amounts in September and the total amount reached $3.2 \mu \mathrm{mol} / \mathrm{g}$. Sato ${ }^{10)}$ reported that $\mathrm{D}$-lactate increased noticeably in the muscle of Yezo abalone by removal form sea-water to the air or exhaustion.

The results of seasonal changes in contents of succinate, malate and acetate are shown in Fig. 4. The total amount of these organic scids was highest in September, followed by December. In September and December the ratio of acetate to the total organic acids was very high. Malate level was nearly constant throughout the year. Succinate which is one of taste-active components was high in amounts from May to September and decreased during winter.

In Table 2 are shown the seasonal changes in contents of free amino acids in the muscle of disk abalone. The total amount of free amino acids was highest in September and decreased to half in other months. The major free amino acids were taurine (Tau), arginine (Arg), glutamine (Gln), glycine (Gly), glutamic acid (Glu), alanine (Ala), and leucine (Leu). In September Gln, Arg, Gly, Glu, Ala, and serine were detected in the largest amounts, compared with other months. The seasonal variation of Tau was not observed and Tau was detected at the level of 1,000 to $1,300 \mathrm{mg} / 100 \mathrm{~g}$ throughout the year. As for the

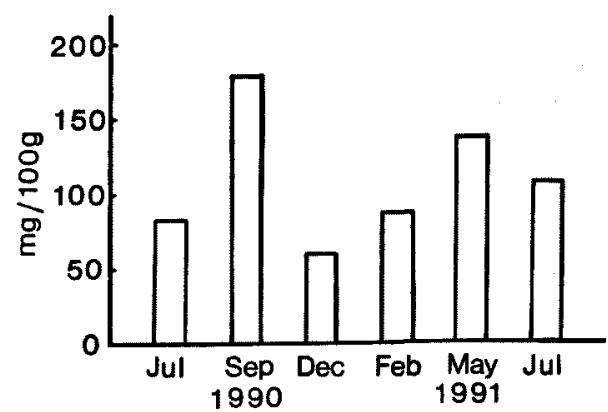

Fig. 5. Seasonal chagnes in content of homarine in the muscle of disk abalone.

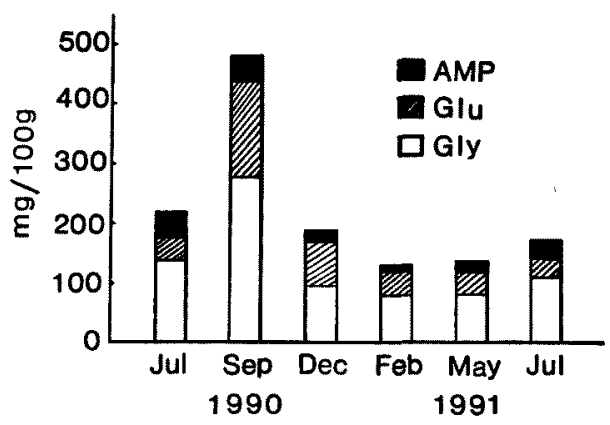

Fig. 6. Seasonal changes in contents of AMP, glutamic acid, and glycine in the muscle of disk abalone.

seasonal variation of free amino acids, there exist the studies on oyster ${ }^{2}$ and ascidian. ${ }^{3,7)}$ In the spawning season the level of Tau increased in oyster, decreased in ascidian, and the levels of Gly, Ala, and Glu increased in both of them.

In Fig. 5 are shown the seasonal changes in content of homarine in the muscle of disk abalone. Homarine content was highest in September and lowest in December. It is reported that homarine content in the muscle and liver of top shell ${ }^{12}$ increased remarkably in summer. Homarine has been reported to participate in the regulation of osmotic pressure. ${ }^{12)}$

The seasonal changes in contents of AMP, Glu, and Gly which are taste-active components ${ }^{13)}$ in the muscle of disk abalone are shown in Fig. 6. The total amount of AMP, Glu, and Gly was highest $(470 \mathrm{mg} / 100 \mathrm{~g})$ in September and lowest $(130 \mathrm{mg} / 100 \mathrm{~g})$ in February. The level of each component was also high in September.

As mentioned above, glycogen level was high (over $6 \%$ ) between July and September (Fig. 2) and succinate was detected in large amounts from summer to early autumn (Fig. 4). Fur- 
thermore, moisture content was very high from December to February (Table 1).

Considering these results inclusively, present study can almost demonstrate that disk abalone is palatable in summer, and watery and unpalatable in winter, which is generally told in Amatsukominato district, Chiba Prefecture. In Amatsukominato district the disk abalone season opens from the middle of May to the middle of September. In this season savoury disk abalone is supplied and Yezo abalone is utilized in winter.

\section{References}

1) I. Takagi and W. Simidu: Seasonal variation of chemical constituents and extractive nitrogens in some species of shellish. Nippon Swisan Gakkaishi, 29, 66-70 (1963).

2) M. Sakaguchi and M. Murata: Seasonal variations of free amino acids in oyster whole body and adductor muscle. Nippon Suisan Gakkaishi, 55, 2037-2041 (1989).

3) M. Matsumoto and H. Yamanaka: Post-mortem biochemical changes in the muscle of kuruma prawn during storage and evaluation of the freshness. Nippon Suisan Gakkaishi, $56,1145-1149$ (1990)

4) S. Sakai: Ecological studies on the abalone, Haliotis discus hannai. Nippon Suisan Gakkaishi, 28, 899-904 (1962).

5) K. Watanabe, H. Uehara, M. Sato, and S. Konosu: Season- al variation of extractive nitrogenous constituents in the muscle of the ascidian Halocynthia roretzi. Nippon Suisan Gakkaishi, 51, 1293-1298 (1985).

6) M. Sakaguchi and W. Simidu: Variation with season and growth in nitrogenous extractives of mackerel muscle. Nippon Suisan Gakkaishi, 31, 72-75 (1965).

7) C. K. Park, T. Matsui, K. Watanabe, K. Yamaguchi, and S. Konosu: Seasonal variation of extractive nitrogenous constituents in ascidian Halocynthia roretzi tissucs. Nippon Suisan Gakkaishi, 56, 1319-1330 (1990).

8) A. Nontratip, S. Wada, and H. Yamanaka: Post-mortem glycolysis and ATP degradation in the muscle of ascidian Halocynthia roretzi. Nippon Suisan Gakkaishi, 57, 761-766 (1991).

9) S. Konosu, K. Watanabe, and K. Yamaguchi: Acceptance effect of taste components. Sensory analysis of taste-active components in the adductor muscle of scallop, in "Food Acceptance and Nutrition" (ed. by L. Solms, D. A. Booth, R. M. Pangborn, and $O$. Raunhardt), Academic Press, London, 1987, pp. 143-155.

10) M. Sato: The role of opines on the anaerobic glycolysis of molluscs. Kagaku to Seibutsu, 28, 82-90 (1990).

11) T. Hirano: On the distribution and seasonal variation of homarine in some marine invertebrates. Nippon Suisan Gakkatshi, 41, 1047-1051 (1975).

12) T. Hirano: Physiological functions and metabolism. 6. Betaines. in "Extractive Components of Fish and Shellfish" (ed. by M. Sakaguchi), Koseishakoseikaku, Tokyo, 1988, pp. $79-89$.

13) S. Konosu: Taste of fish and shellfish with special reference to taste-producing substances. Nippon Sholuhin Kogyo Gakkaishi 20, 432-439 (1973). 